\title{
Sensitization to individual allergens and bronchial responsiveness in the ECRHS
}

\author{
S. Chinn, P. Burney, J. Sunyer, D. Jarvis, C. Luczynska, on behalf of the \\ European Community Respiratory Health Survey
}

Sensitization to individual allergens and bronchial responsiveness in the ECRHS. European Community Respiratory Health Survey. (C)ERS Journals Ltd 1999.

ABSTRACT: Little is known about the relation of bronchial responsiveness (BHR) to sensitization to individual allergens, or its variation between countries.

Data were obtained for BHR, specific immunoglobulin $E$ and confounding variables from 11,215 subjects, aged 20-44 yrs at the start of the European Community Respiratory Health Survey, in 34 centres in 15 countries. The relation of BHR to sensitization to cat, house dust mite, timothy grass and Cladosporium was estimated by means of multiple regression for each centre, and combined across centres by random effects meta-analysis, controlling for baseline lung function, height, sex, season of testing, age, smoking and age/sex and age/smoking interactions.

BHR was greater, on average, in those sensitized to cat $(p=0.023)$, house dust mite $(\mathrm{p}<0.001)$ and timothy grass $(\mathrm{p}=0.018)$, but not to Cladosporium $(\mathrm{p}=0.60)$, and increased with degree of sensitization $(p<0.001)$. All relations showed heterogeneity between centres, although to a lesser extent in the relation to sensitization to house dust mite.

More variation in bronchial responsiveness was explained by sensitization and degree of sensitization to the individual allergens than by atopy defined as any positive test in each centre, but the relative importance of each allergen varied. The use of atopy as a single variable in relation to bronchial hyperresponsiveness may be misleading.

Eur Respir J 1999; 14: 876-884.

The identification of risk factors for bronchial responsiveness (BHR) is important in furthering the understanding of the causes of asthma and of chronic obstructive lung disease. Although not synonymous with asthma, BHR has been widely used as an objective marker, especially in young adults and children. BHR has been shown to vary widely throughout Europe and elsewhere [1], with the highest levels being recorded in the UK and New Zealand. The reasons for this variation are unknown. BHR is known to be related to atopy [2-7], and the prevalence of atopy is also highly variable, with estimates ranging $16-45 \%$ [8]. However, atopy has been expressed in different ways, either as a positive skin-prick test or the presence of serum-specific immunoglobulin $\mathrm{E}$ ( $\operatorname{IgE}$ ) to any of a number of common allergens, or as the number of positive results. These definitions depend on the number of allergens tested.

Few studies have examined the relation of BHR to sensitization to individual allergens. Some information is available for adults in Norway [6], young adults in Spain [4] and England [9], and children in Australia [10] and New Zealand $[11,12]$. A wider age range of subjects was studied in the Netherlands [5], but allergens were analysed one at a time, and the independent effects were not estimated. Even in the largest of these studies [4], in which 1,816 subjects were included in the analyses, there was limited power to assess the independent effects of sensitization to the separate allergens. In England, there is some evidence that BHR may have a different relation to sensitization to individual allergens [9], in Norway [6], England [9] and Australia [10], there is evidence for a relation of BHR to degree of sensitization to house dust mite, and in New Zealand [12] to degree of sensitization to several allergens.

The extent to which variation in atopy explains variation in BHR between countries is unknown. In order to investigate this, the relation of BHR to sensitization to different allergens needs to be established, using a common set of allergens in each country. A simple description of the extent to which variation in atopy explains variation in BHR will depend on one relation of BHR to each allergen being the same for each country.

For some countries the findings [4, 9] in the data from the European Community Respiratory Health Survey (ECRHS) were obtained using slightly different methodology, and no corresponding results for adults have been given for others. Data for BHR and specific IgE to four allergens were obtained for young adults in 34 centres in 15 countries in the ECRHS. This paper reports the relations of BHR to sensitization and degree of sensitization to the four common allergens in this large sample, investigates the variation in the relations between the centres, and the variation within centres. The implications for the reporting of atopy in future studies are discussed. 


\section{Methods}

\section{Sampling}

The protocol for the ECRHS has been described in detail elsewhere $[13,14]$. Briefly, participating centres selected an area defined by pre-existing administrative boundaries with a population of $\geq 150,000$. Where possible, ail up-to-date sampling frame was used to select randomly $\geq 1,500$ males and 1,500 females aged 20-44 yrs. During stage I, subjects were sent a questionnaire enquiring about respiratory symptoms and attacks of asthma in the last 12 months, current use of asthma medication and nasal allergies including hay fever. A random sample of subjects were selected to take part in stage II. Those who had already responded to stage I were invited to answer a more detailed administered questionnaire, and to take part in blood tests, skin tests, assessment of lung function by means of spirometry and airway challenge with methacholine. The questionnaire collected information on current smoking and smoking history.

\section{Methacholine challenge}

This has been described in detail elsewhere $[1,9,14]$. BHR to methacholine was measured in eligible subjects using one of two dosing schedules, one delivering methacholine to a maximum dose of $1 \mathrm{mg}$ and the other to a maximum of $2 \mathrm{mg}$. Methacholine was delivered via a Mefar dosimeter (Mefar, Bovezzo, Italy), forced expiratory volume in one second (FEV1) recorded 2 min after each inhalation and the test stopped when either a $20 \%$ fall in FEV1 had been achieved or the final dose given. Only data from the doses common to the two schedules, $0.0078-1 \mathrm{mg}$ cumulative dose, were used in the multicentre analyses [1].

\section{Total and specific immunoglobulin E}

Serum total IgE and specific IgE to cat, house dust mite (Dermatophagoides pteronyssinus), Cladosporium and timothy grass were measured using the Pharmacia CAP system (Pharmacia, Uppsala, Sweden). The measurement range for total $\mathrm{IgE}$ was $2-2,000 \mathrm{kU} \cdot \mathrm{L}^{-1}$, and for specific IgE $0.35-100 \mathrm{kUA} \cdot \mathrm{L}^{-1}$ (allergen specific units). Specific IgE results were regarded as positive if $>0.35 \mathrm{kUa} \cdot \mathrm{L}^{-1}$. Total IgE activity was logarithmically transformed. Specific IgE to birch, included in the analysis of the English data [9], was not tested for in all centres [8], and has not been included here. Presence of atopy was defined as a positive specific $\operatorname{IgE}$ to at least one of the four allergens.

\section{Statistical analysis}

The measure of dose/response slope, adopted for between centre analyses in the ECRHS $[1,15]$, was used as the main measure of BHR, but the provocative dose causing a $20 \%$ fall in FEV1 (PD20) was also analysed. The log slope, calculated by means of regressing percentage fall in FEV1 on $\log 10$ dose [15], required transformation in order to satisfy the assumptions of standard statistical analysis, i.e. normality and homogeneity of variance; the transformation $100 /(\log$ slope+10) was found to be appropriate [16]. The term "slope" is used for transformed log slope as used in the ECRHS [1], with a low slope indicative of high BHR. The PD20 was estimated by fitting an exponential curve to the decline in maximum FEV1 with log dose [17].

Variables found to be risk factors for BHR additional to specific IgE in the analysis of the English data [9] were included. These were age, smoking and an age/smoking interaction, height, sex, and baseline FEV1 expressed as a standardized difference from an internally derived predicted value, and as a percentage of forced vital capacity. An age/sex interaction was added as participation rates varied by age and sex across centres. In addition, season of testing, total $\operatorname{IgE}$ and specific IgE titres against all four allergens were included, as increased BHR was found with increasing titre against $D$. pteronyssinus in the English data [9], and that analysis lacked the power to detect a relation with antibody titres to other allergens. Internal predicted values were used because the published standards [18] were found, on average, to underestimate FEV1 for almost all centres [19].

"Slope" was analysed using multiple linear regression and the proportion with a PD20 $<1 \mathrm{mg}$ by means of multiple logistic regression. Analyses were carried out by centre for "slope" and by country for PD20, the results being combined in a random effects meta-analysis [20]. The relation of BHR to each titre of specific $\operatorname{IgE}$ was studied first; if no heterogeneity or significant effect was detected, the variable was omitted from subsequent analyses. Otherwise relations to all variables were mutually adjusted. In cases in which a titre was retained in the model, 0.35 was subtracted from its value so that the estimate for "sensitization" was an estimate of the relation of "slope" to sensitization at the minimum positive level.

The variation in "slope" explained by all variables and all variables except for specific IgE, the decrease in variation on omitting sensitization to each allergen in turn, and that explained by using atopy as a single variable were estimated for each centre.

\section{Results}

\section{Study population}

One centre with BHR data did not take part in the serum testing for IgE, one centre had a problem with the Mefar dosimeter and two centres included in the analysis of total and specific IgE data were not included in further analyses of stage II data as these were not fully checked and edited. One centre with BHR data carried out stage II too late to have sera tested for IgE. Out of the 35 centres with BHR data [1] and 37 with IgE data [8], there were, therefore, 34 for which both were usable, from 15 countries. Table 1 gives the numbers of subjects in each centre with $\operatorname{IgE}$ and BHR data and both. In most centres, unwillingness to undertake BHR testing, ineligibility or inability to complete the test limited the data available, but, in some centres, the response to venepuncture was lower than that achieved for BHR. Details of the response to BHR testing are given elsewhere [1]. Most of the 11,409 subjects with both sets of data had complete data for the other variables; there were 11,215 subjects in the analysis.

BHR as measured by mean "slope" and prevalence of PD20 $<1 \mathrm{mg}$, prevalence of a measurable IgE to each specific allergen and prevalence of atopy as defined are given by country in table 2 , for subjects with both BHR and total 
Table 1. - Number of randomly selected subjects with immunoglobulin $\mathrm{E}$ ( $\mathrm{IgE}$ ) and bronchial hyperresponsiveness (BHR) data

\begin{tabular}{|c|c|c|c|}
\hline \multirow[b]{2}{*}{ Centre } & \multicolumn{3}{|c|}{ Subjects $\mathrm{n}$} \\
\hline & $\operatorname{IgE}$ & BHR & Both \\
\hline Reykjavík, Iceland & 518 & 469 & 456 \\
\hline Bergen, Norway & 749 & 556 & 545 \\
\hline Gothenburg, Sweden & 573 & 545 & 521 \\
\hline Umeå, Sweden & 425 & 420 & 378 \\
\hline Uppsala, Sweden & 525 & 498 & 475 \\
\hline Bergen op Zoom, the Netherlands & 418 & 402 & 379 \\
\hline Geleen, the Netherlands & 388 & 345 & 339 \\
\hline Groningen, the Netherlands & 355 & 339 & 321 \\
\hline Antwerp city, Belgium & 267 & 289 & 230 \\
\hline South Antwerp, Belgium & 325 & 315 & 282 \\
\hline Erfurt, Germany & 718 & 596 & 583 \\
\hline Hamburg, Germany & 775 & 1012 & 750 \\
\hline Basle, Switzerland & 567 & 654 & 436 \\
\hline Bordeaux, France & 512 & 464 & 435 \\
\hline Grenoble, France & 429 & 413 & 383 \\
\hline Montpellier, France & 364 & 355 & 292 \\
\hline Paris, France & 555 & 518 & 451 \\
\hline Cambridge, UK & 192 & 175 & 147 \\
\hline Ipswich, UK & 365 & 345 & 310 \\
\hline Norwich, UK & 365 & 340 & 308 \\
\hline Dublin, Ireland & 232 & 286 & 210 \\
\hline Pavia, Italy & 250 & 233 & 195 \\
\hline Turin, Italy & 177 & 194 & 160 \\
\hline Verona, Italy & 332 & 290 & 283 \\
\hline Albacete, Spain & 390 & 347 & 315 \\
\hline Barcelona, Spain & 175 & 178 & 149 \\
\hline Galdakao, Spain & 365 & 364 & 333 \\
\hline Huelva, Spain & 215 & 203 & 156 \\
\hline Oviedo, Spain & 244 & 239 & 221 \\
\hline Christchurch, New Zealand & 268 & 304 & 237 \\
\hline Hawke's Bay, New Zealand & 142 & 166 & 120 \\
\hline Wellington, New Zealand & 301 & 312 & 254 \\
\hline Melbourne, Australia & 520 & 511 & 480 \\
\hline Portland, OR, USA & 314 & 337 & 275 \\
\hline Total & 13310 & 13014 & 11409 \\
\hline
\end{tabular}

IgE data. BHR was greatest in Australia and New Zealand, shown by the lowest mean "slopes" and highest prevalences of PD20 <1 mg. BHR was lowest in Iceland, i.e. the mean slope was highest. Of the four allergens, sensitization to Cladosporium was the least common, followed by sensitization to cat. The relative prevalences of sensitization to house dust mite and timothy grass varied between countries. Between centre variation was even greater than that between countries.

Relation of bronchial hyperresponsiveness to sensitization, heterogeneity between centres

All relations showed significant $(\mathrm{p}<0.05)$ heterogeneity except that to sensitization to house dust mite. Those showing strong evidence $(p<0.01)$ of heterogeneity are illustrated in the figures. Figure 1 shows the effect of increasing cat-specific IgE titre on slope, excluding the estimate for Huelva, Spain, which had extremely wide confidence intervals and added virtually no information to that from the other 33 centres. No centre had a positive gradient that was statistically significant, which would have indicated a decrease in BHR with increasing sensitization. Reykjavík, Gothenburg and Paris had a greater negative gradient than the mean and Groningen, Grenoble and Galdakao a more positive gradient. Despite the significant heterogeneity $(\mathrm{p}<0.001)$, the random effects estimate of the mean relation was negative $(\mathrm{p}<0.001)$, showing an increase in BHR with increasing titre.

The relation to Cladosporium-specific IgE titre showed no heterogeneity, and the combined estimate of the regression coefficient was not significantly different from zero. Four centres (Albacete, Spain; Pavia and Verona, Italy; Hawke's Bay, New Zealand) were omitted from this analysis as Cladosporium-specific IgE titre was completely confounded by other data. Cladosporium-specific IgE titre was omitted from further analyses of slope. The heterogeneity in the relation of BHR to sensitization to Cladosporium $(\mathrm{p}=0.001)$ is illustrated in figure 2 , which shows that slope decreased significantly with sensitization in Gothenburg, Sweden and in Cambridge and Ipswich, UK, and increased in Bergen op Zoom, the Netherlands, Barcelona, Spain and Christchurch, New Zealand. The mean relation was not significantly different from zero $(\mathrm{p}=$ $0.60)$.

The relations of BHR to specific IgE titres to timothy grass and house dust mite also showed some heterogeneity ( $p=0.021$ and 0.013 , respectively), and the mean relations were significantly negative $(\mathrm{p}=0.01$ and $\mathrm{p}<0.001)$. Hence, for cat, timothy grass and house dust mite, the estimate for sensitization is adjusted for titre and represents the effect of sensitization at the minimum level. For cat sensitization, the estimates for most centres were compatible with an increase in BHR in sensitized subjects (fig. 3, omitting Huelva), but for South Antwerp the estimate of the increase in slope was positive, with a confidence interval (CI) that excluded zero. However, for increasing titre, the estimate was negative (fig. 1), and both CIs were wide, so this may be a consequence of the difficulty in separating the information. The heterogeneity was highly significant $(\mathrm{p}=0.001$ ), but the $95 \%$ CI for the effect of minimum sensitization only just excluded zero $(\mathrm{p}=0.023)$. The heterogeneity in the relation of BHR to sensitization to timothy grass is shown in figure 4, in which CIs are narrower due to the greater prevalence of sensitization. Of the centres with a positive estimate of the increase in slope, i.e. a decrease in BHR with increasing sensitization, only Reykjavík had a CI that excluded zero.

\section{Relation of bronchial hyperresponsiveness to sensitiza-} tion, random effects estimates

The meta-analysis results for BHR slope are shown in table 3 . In addition to the results described in the figures, it can be seen that the average relation of "slope" to timothy grass-specific IgE titre was less than that for cat or house dust mite, and, that the relation to sensitization to house dust mite was comparable to that for cat, but with a narrower CI. The relation of "slope" to log serum total IgE was negative and highly significant with little heterogeneity. (A one unit increase in $\log 10$ total $\mathrm{IgE}$ is equivalent to a 10 -fold increase in $\mathrm{kU} \cdot \mathrm{L}^{-1}$.)

The analyses were repeated using logistic regression for the proportion of subjects with PD20 $<1 \mathrm{mg}$. Owing to collinearity it was not possible to carry out these analyses by centre, the dichotomous variable providing less information than "slope", so analysis was carried out by country. Even then the analysis of Cladosporium-specific IgE titre required the omission of Spain, Ireland, Italy and 
Table 2. - "Slope", total immunoglobulin ( $\mathrm{IgE})$ and prevalence of provocative dose of methacholine causing a $20 \%$ fall in forced expiratory volume in one second (PD20) $<1.0 \mathrm{mg}$ and of specific IgE to four allergens for subjects with BHR data in the 15 countries included in the study

\begin{tabular}{|c|c|c|c|c|c|c|c|c|}
\hline \multirow[b]{2}{*}{ Country } & \multicolumn{2}{|c|}{ BHR } & \multicolumn{5}{|c|}{ Specific $\operatorname{IgE}$} & \multirow[b]{2}{*}{$\begin{array}{c}\text { Total Ige } \\
\text { GM }\end{array}$} \\
\hline & $\begin{array}{l}\text { "Slope" } \\
\text { mean }\end{array}$ & $\begin{array}{c}\text { PD20 } \\
<1.0 \mathrm{mg} \\
\%\end{array}$ & $\begin{array}{c}\text { Cat } \\
\%\end{array}$ & $\begin{array}{c}\mathrm{HDM} \\
\%\end{array}$ & $\begin{array}{c}\text { Timothy grass } \\
\%\end{array}$ & $\begin{array}{c}\text { Cladosporium } \\
\%\end{array}$ & $\begin{array}{c}\text { Any } \\
\%\end{array}$ & \\
\hline Iceland & 8.35 & 7.0 & 7.2 & 9.0 & 11.8 & 6.4 & 21.5 & 13.2 \\
\hline Norway & 7.72 & 7.9 & 7.3 & 13.2 & 14.9 & 1.8 & 23.9 & 25.3 \\
\hline Sweden & 7.84 & 9.4 & 13.7 & 9.6 & 17.6 & 2.2 & 29.1 & 23.3 \\
\hline The Netherlands & 7.58 & 12.4 & 8.0 & 27.1 & 20.0 & 4.1 & 36.1 & 33.2 \\
\hline Belgium & 7.53 & 12.7 & 8.6 & 24.0 & 15.6 & 4.1 & 33.2 & 29.4 \\
\hline Germany & 7.47 & 13.4 & 9.6 & 16.9 & 23.4 & 4.4 & 35.2 & 30.9 \\
\hline Switzerland & 7.97 & 8.7 & 14.4 & 17.7 & 33.7 & 7.3 & 41.1 & 28.1 \\
\hline France & 7.25 & 17.6 & 7.9 & 23.6 & 16.6 & 2.4 & 32.3 & 50.1 \\
\hline UK & 7.23 & 19.1 & 8.9 & 23.4 & 24.2 & 2.5 & 37.5 & 27.2 \\
\hline Ireland & 7.38 & 16.7 & 7.6 & 33.3 & 15.2 & 1.9 & 40.0 & 46.5 \\
\hline Italy & 7.98 & 9.9 & 5.3 & 11.9 & 17.9 & 1.1 & 25.4 & 44.8 \\
\hline Spain & 7.92 & 11.4 & 5.1 & 17.5 & 11.6 & 2.3 & 25.3 & 34.9 \\
\hline New Zealand & 7.04 & 24.4 & 9.7 & 32.0 & 26.4 & 2.0 & 42.3 & 41.1 \\
\hline Australia & 7.01 & 21.5 & 9.0 & 31.3 & 29.2 & 2.5 & 44.8 & 37.5 \\
\hline USA & 7.22 & 18.2 & 11.3 & 19.6 & 32.7 & 4.4 & 42.9 & 22.7 \\
\hline
\end{tabular}

HDM: house dust mite; GM: geometric mean.

Switzerland, and for Cladosporium sensitization omission of Spain and Ireland. Heterogeneity appeared less marked than with "slope", but this can be attributed to the lower power of the logistic analysis. Otherwise the results were in accordance in the two analyses.

BHR showed marked heterogeneity in its relation to catspecific IgE titre and to sensitization to cat. Inspection of the data showed that centres with a positive relation for one tended to have a negative relation for the other. This suggested that the heterogeneity might be artefactual to some extent; thus, the cat sensitization analysis was repeated unadjusted for titre, which estimated the association with any sensitization and not one at the minimum level of detection, as in table 3. As expected, the relation, 0.506

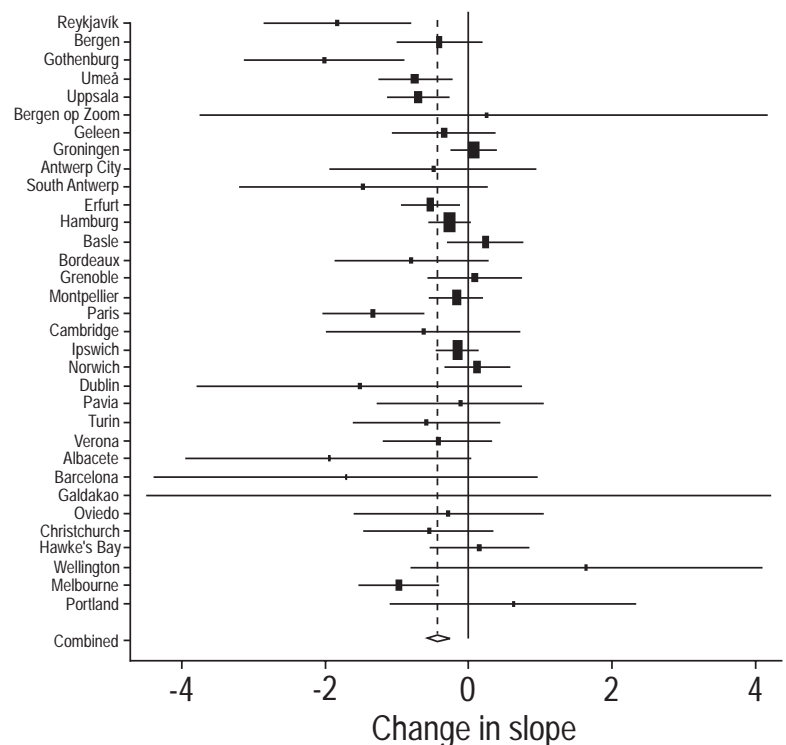

Fig. 1. - Change in "slope" per $10 \mathrm{kUA} \cdot \mathrm{L}^{-1}$ increase in specific $\operatorname{IgE}$ titre to cat allergen $>0.35 \mathrm{kUA} \cdot \mathrm{L}^{-1}$, by centre (Huelva, Spain omitted). The area of each rectangle is proportional to the reciprocal of the variance of the estimate for the centre. - - - : combined random effects estimate; $\diamond$ : width of its $95 \%$ confidence interval. Locations of centres are shown in table 1
(95\% CI $-0.725--0.287, \mathrm{p}<0.001)$, was stronger than for minimal sensitization, with heterogeneity $(p<0.001)$ again detected. There was little change in the ranking of the centres shown in figure 3 . Sensitization to cat in South Antwerp was still associated with a decrease in BHR.

\section{Patterns of sensitization}

The results of the above analyses depend on the additivity of the effects of sensitization to the individual allergens. The prevalence of each combination of sensitization is shown in table 4 by country, for subjects with data for BHR as well as for specific IgE. Sensitization to house dust mite alone was the most prevalent in approximately half of the countries and that to timothy grass alone in the

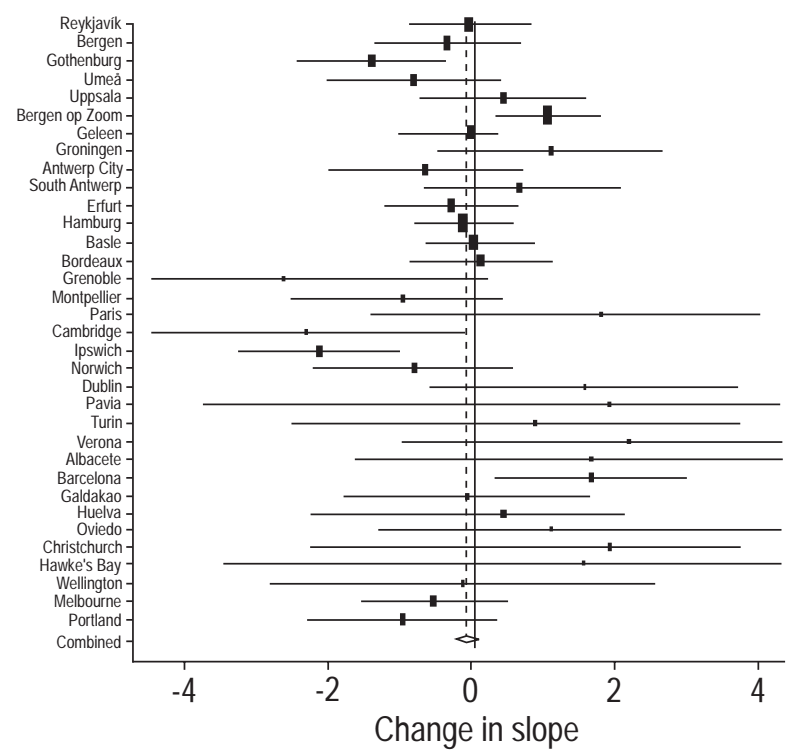

Fig. 2. - Change in "slope" in those sensitized to Cladosporium with a specific $\operatorname{IgE}$ titre of $\geq 0.3510 \mathrm{kUA} \cdot \mathrm{L}^{-1}$, by centre. The area of each rectangle is proportional to the reciprocal of the variance of the estimate for the centre. $---:$ combined random effects estimate; $\diamond:$ width of its $95 \%$ confidence interval. Locations of centres are shown in table 1. 


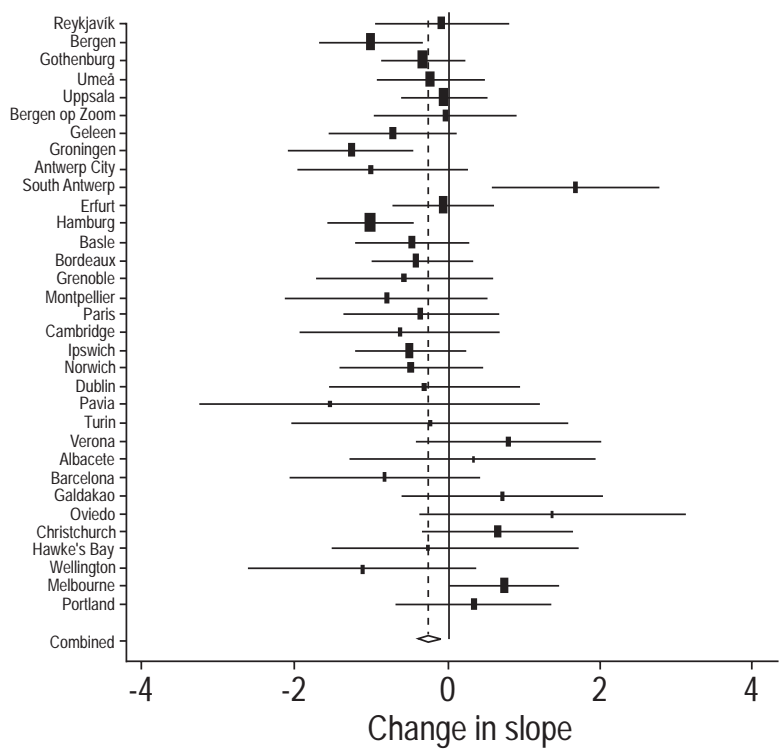

Fig. 3. - Change in "slope" in those sensitized to cat allergen at the minimum detectable level, by centre (Huelva, Spain omitted). The area of each rectangle is proportional to the reciprocal of the variance of the estimate for the centre. --- : combined random effects estimate; $\diamond$ : width of its $95 \%$ confidence interval. Locations of centres are shown in table 1 .

remainder. Sensitization to house dust mite in combination with grass sensitization, or both cat and grass sensitization, was more common than cat sensitization alone or with either of the other two allergens. Sensitization to Cladosporium was rare so combinations with other allergen sensitization have not been separated.

The results of meta-analyses of the relation of mean "slope" to each of the more prevalent combinations are given in table 5. These show that the increase in BHR was greater in subjects sensitized to all three allergens than in those sensitized to two, which in turn was greater than the

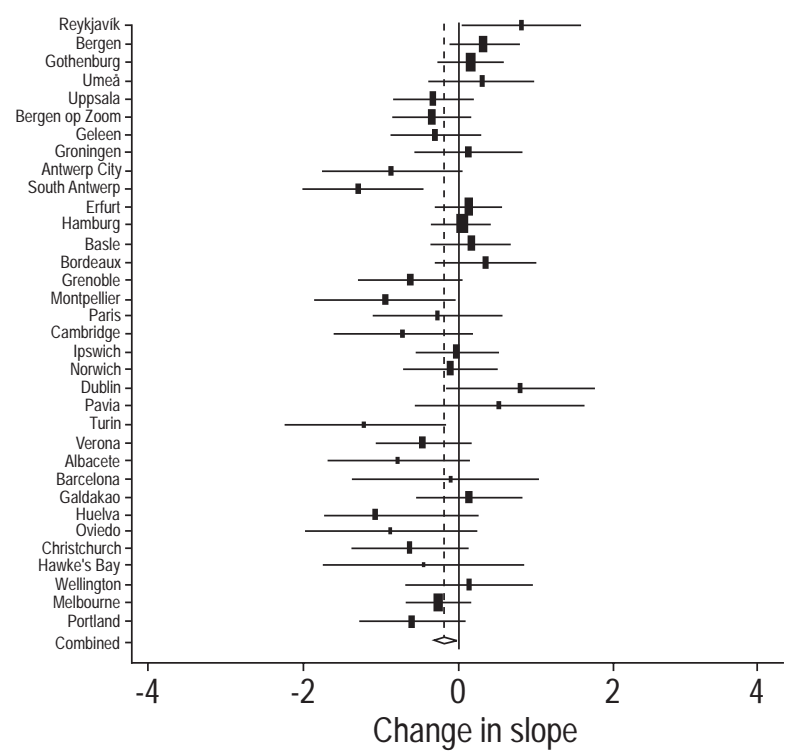

Fig. 4. - Change in "slope" in those sensitized to timothy grass at the minimum detectable level, by centre. The area of each rectangle is proportional to the reciprocal of the variance of the estimate for the centre. $-{ }_{-}$: combined random effects estimate; $\diamond$ : width of its $95 \%$ confidence interval. Locations of centres are shown in table 1. increase in those sensitized to just one. However, within these groups, there were differences, a greater reduction in "slope" being associated with sensitization to cat alone than to grass alone, and to cat with house dust mite than to cat with grass. Not all centres had sufficient subjects in each sensitization group, and so the number of centres was reduced in the analyses. The results shown in table 5 were not adjusted for the degree of sensitization.

\section{Relation of bronchial hyperresponsiveness to sensitiza- tion to timothy grass by season}

Subjects were tested throughout the year, and those sensitized to timothy grass would be expected to show a greater increase in BHR when tested in the grass pollen season. As this can extend from May to October in some European countries [21], "summer" was defined as encompassing these months in the northern hemisphere and November to April in the southern hemisphere. Subjects sensitized to timothy grass, who were tested in summer, had a mean "slope" - 0.29 (95\% CI -0.47- -0. 11) from that of unsensitized subjects tested in the same season, and for those tested in winter the mean difference was -0.12 ($0.36-0.12)$. Testing for interaction between sensitization and summer/winter testing showed some evidence for a difference in the two estimates $(\mathrm{p}=0.13)$. There was little evidence for heterogeneity between centres in the interaction term $(\mathrm{p}=0.21)$. There was evidence for heterogeneity between centres in the "winter" estimate $(p=0.001)$. The estimates for the relation of BHR to degree of sensitization were almost identical in the winter- and summertested subjects $\left(-0.009\right.$ and -0.008 per $10 \mathrm{kUa} \cdot \mathrm{L}^{-1}$, respectively), with stronger evidence for heterogeneity between centres in this in the "summer" estimate $(\mathrm{p}=$ $0.001)$ than in the "winter" estimate $(p=0.01)$.

\section{Population effects}

Table 6 shows the variation in "slope" accounted for by various models. Each model included log total IgE, season of testing, baseline lung function, height, sex, age, smoking and age/sex and age/smoking interactions. The first column shows the percentage variation explained by these variables alone, which ranged from $11.4 \%$ in Antwerp City, Belgium to $33.9 \%$ in Cambridge, UK. The second shows the variation explained by these variables plus the seven variables for specific IgE, the titres for house dust mite, cat and timothy grass, and sensitization at the minimum positive level to these three and any sensitization to Cladosporium. The difference in these two columns, the variation explained by all the specific IgE variables, ranged from $1.4 \%$ in Erfurt, Germany to $12.7 \%$ in Ipswich, UK. The next three columns show the reduction in variation on omitting the two variables for house dust mite, cat and timothy grass in turn, and the sixth column the reduction on leaving out Cladosporium sensitization. The relative importance of the four allergens varied between centres, with house dust mite sensitization explaining the greatest variation in 16 centres, cat in nine including equally with house dust mite in one centre, timothy grass in eight and Cladosporium in just two, Cambridge, UK and Barcelona, Spain. The final column shows the loss of explanatory power when atopy defined as any positive specific IgE replaced the seven variables. Not 
Table 3. - Random effects meta-analyses by centre of mutually adjusted* associations of "slope" with individual allergens

\begin{tabular}{|c|c|c|c|c|c|}
\hline \multirow[b]{2}{*}{ Variable } & \multicolumn{2}{|c|}{ Heterogeneity } & \multirow[b]{2}{*}{ Regression coefficient } & \multirow[b]{2}{*}{$95 \% \mathrm{CI}$} & \multirow[b]{2}{*}{ p-value } \\
\hline & df & p-value & & & \\
\hline \multicolumn{6}{|c|}{ Allergen titres per $10 \mathrm{kUA} \cdot \mathrm{L}^{-1}$ increase } \\
\hline Cladosporium $^{+}$ & 29 & 0.332 & 0.103 & $-1.132-1.337$ & 0.87 \\
\hline Cat & 33 & $<0.001$ & -0.425 & $-0.612--0.239$ & $<0.001$ \\
\hline Timothy grass & 33 & 0.021 & -0.103 & $-0.166--0.040$ & 0.001 \\
\hline House dust mite & 33 & 0.013 & -0.349 & $-0.426--0.272$ & $<0.001$ \\
\hline \multicolumn{6}{|c|}{ Allergen sensitization ${ }^{\#}$} \\
\hline Cladosporium $^{+}$ & 33 & 0.001 & -0.092 & $-0.434-0.250$ & 0.60 \\
\hline Cat & 33 & 0.001 & -0.269 & $-0.501--0.037$ & 0.023 \\
\hline Timothy grass & 33 & 0.002 & -0.190 & $-0.346--0.033$ & 0.018 \\
\hline House dust mite & 33 & 0.418 & -0.254 & $-0.364--0.144$ & $<0.001$ \\
\hline $\log _{10}$ total $\operatorname{IgE}$ & 33 & 0.177 & -0.156 & $-0.224--0.088$ & $<0.001$ \\
\hline
\end{tabular}

*: adjusted for season of testing, baseline lung function, height, sex, age, smoking and age/sex and age/smoking interactions; ${ }^{+}$: no evidence for heterogeneity or nonzero effect, omitted in other analyses in this table; ${ }^{\#}$ : for cat, timothy grass and house dust mite, estimate for minimum positive sensitization. df: degrees of freedom; CI: confidence interval; IgE: immunoglobulin E.

only was the loss generally greater than that obtained on omitting any single specific IgE, except cat in Hamburg, Germany, timothy grass in Turin, Italy and house dust mite in Galdakao, Spain, but for most centres (not shown) it was greater than that explained by house dust mite, cat or timothy grass alone. In three centres, Reykjavk, Iceland, Erfurt, Germany and Barcelona, Spain, the variation explained by the single atopy variable was $<0.1 \%$. Analysis of data from the subjects tested in the summer months did not greatly change the relative importance of the four allergens.

\section{Discussion}

The analyses showed heterogeneity in the relation of BHR to sensitization to Cladosporium, cat and timothy grass, and to a lesser extent to house dust mite, and variation in the relative importance of the four allergens across centres in the ECRHS. House dust mite sensitization explained the greatest variation in BHR in nearly half of the centres. A single "atopy" variable generally explained less variation than specific IgE to a single allergen, due to not allowing for degree of sensitization, and opposing directions of the relations in some centres.
Studies which have analysed the independent effects of sensitization to several allergens have all reported an effect of house dust mite [4, 6, 9-12]. In addition, a relation to degree of sensitization to house dust mite was reported in four studies $[6,9,10,12]$, and to sensitization to cat, dog or Aspergillus fumigatus in 13-yr-old New Zealander children [12]. BHR was significantly increased in young adults in Spain with sensitization to olive or timothy grass [4], in England with sensitization to cat, timothy grass and Cladosporium [9], and in children aged 8-11 yrs in Australia sensitized to ryegrass or cockroach [10].

Even variation in the relative importance of sensitization to different allergens cannot be reliably deduced from these separate reports. First, there was great variation in the number and type of allergens that were included. Specific IgE to a maximum of five allergens was tested $[4,6,9]$, but the use of skin-prick tests enabled more allergens to be included $[4,10,11]$. Secondly, there was limited power in these individual studies to detect a significant relation to the less common allergens, particularly if most subjects sensitized to these allergens were also sensitized to the common allergens. Hence, lack of significance in a multiple linear or multiple logistic regression does not rule

Table 4. - Prevalence of the most frequently occurring combinations of sensitization to house dust mite (HDM), timothy grass, cat and Cladosporium in subjects with bronchial hyperresponsiveness data, by country

\begin{tabular}{|c|c|c|c|c|c|c|c|c|c|}
\hline Country & $\begin{array}{c}\text { HDM only } \\
\%\end{array}$ & $\begin{array}{c}\text { Grass only } \\
\%\end{array}$ & $\begin{array}{c}\mathrm{HDM}+\text { grass } \\
\%\end{array}$ & $\underset{\%}{\mathrm{HDM}}+\underset{\%}{\operatorname{grass}}+\mathrm{cat}$ & $\begin{array}{c}\text { Cat only } \\
\%\end{array}$ & $\begin{array}{c}\text { Grass }+ \text { cat } \\
\%\end{array}$ & $\begin{array}{c}\mathrm{HDM}+\mathrm{cat} \\
\%\end{array}$ & $\begin{array}{c}\text { Other* } \\
\%\end{array}$ & $\begin{array}{c}\text { None } \\
\%\end{array}$ \\
\hline Iceland & 3.7 & 5.0 & 1.1 & 0.7 & 2.2 & 2.0 & 0.4 & 6.4 & 78.5 \\
\hline Norway & 5.7 & 7.2 & 2.9 & 2.4 & 1.5 & 1.1 & 1.3 & 1.8 & 76.2 \\
\hline Sweden & 4.5 & 8.3 & 1.6 & 1.8 & 5.5 & 4.4 & 0.8 & 2.2 & 70.9 \\
\hline The Netherlands & 12.6 & 5.7 & 6.7 & 3.5 & 1.1 & 0.9 & 1.5 & 4.1 & 63.9 \\
\hline Belgium & 12.1 & 5.3 & 4.5 & 3.5 & 1.6 & 0.8 & 1.4 & 4.1 & 66.8 \\
\hline Germany & 7.1 & 11.8 & 4.0 & 2.9 & 2.0 & 2.4 & 0.7 & 4.4 & 64.8 \\
\hline Switzerland & 4.1 & 15.6 & 4.4 & 4.8 & 1.4 & 2.8 & 0.7 & 7.3 & 58.9 \\
\hline France & 12.6 & 6.1 & 4.7 & 2.6 & 0.8 & 1.2 & 1.9 & 2.4 & 67.7 \\
\hline UK & 9.9 & 10.2 & 6.9 & 4.1 & 1.8 & 1.2 & 0.9 & 2.5 & 62.5 \\
\hline Ireland & 19.5 & 3.8 & 7.6 & 2.9 & 1.9 & 0.0 & 2.4 & 1.9 & 60.0 \\
\hline Italy & 6.1 & 10.4 & 3.1 & 1.6 & 0.8 & 2.0 & 0.3 & 1.1 & 74.6 \\
\hline Spain & 10.7 & 5.4 & 3.1 & 1.5 & 0.8 & 0.6 & 0.9 & 2.3 & 74.7 \\
\hline New Zealand & 13.3 & 8.2 & 10.2 & 5.6 & 1.0 & 0.8 & 1.3 & 2.0 & 57.7 \\
\hline Australia & 13.8 & 11.3 & 8.8 & 6.0 & 0.2 & 1.5 & 0.8 & 2.5 & 55.2 \\
\hline USA & 6.5 & 15.3 & 6.5 & 4.0 & 2.9 & 2.9 & 0.4 & 4.4 & 57.1 \\
\hline
\end{tabular}

*: all combinations with sensitization to Cladosporium. 
Table 5. - Random effects meta-analyses by centre of associations* of "slope" with combinations of sensitization compared to none

\begin{tabular}{|c|c|c|c|c|c|}
\hline \multirow[b]{2}{*}{ Sensitization $^{+}$} & \multicolumn{2}{|c|}{ Heterogeneity } & \multirow[b]{2}{*}{ Estimate } & \multirow[b]{2}{*}{$95 \% \mathrm{CI}$} & \multirow[b]{2}{*}{ p-value } \\
\hline & $\mathrm{df}$ & $\mathrm{p}$-value & & & \\
\hline HDM only & 33 & 0.005 & -0.397 & $-0.570--0.222$ & $<0.001$ \\
\hline Grass only & 33 & 0.023 & -0.282 & $-0.455--0.113$ & 0.001 \\
\hline Cat only & 31 & 0.039 & -0.650 & $-1.000--0.300$ & $<0.001$ \\
\hline HDM+grass & 33 & 0.112 & -0.861 & $-1.069--0.652$ & $<0.001$ \\
\hline Grass+cat & 29 & 0.117 & -0.644 & $-0.973--0.314$ & $<0.001$ \\
\hline $\mathrm{HDM}+\mathrm{cat}$ & 31 & 0.004 & -1.368 & $-1.843--0.894$ & $<0.001$ \\
\hline $\mathrm{HDM}+$ grass + cat & 33 & 0.289 & -1.539 & $-1.778--1.299$ & $<0.001$ \\
\hline
\end{tabular}

*: adjusted for season of testing, baseline lung function, height, sex, age, smoking and age/sex and age/smoking interactions; ${ }^{+}:$titre $>0.35 \mathrm{kUA} \cdot \mathrm{L}^{-1}$. df: degrees of freedom; $\mathrm{CI}$ : confidence interval; HDM: house dust mite.

out a relation. Conversely, a significant univariate relation with a particular allergen may result from the relation of BHR to another allergen to which most of the subjects are sensitized. Thirdly, different cut-off points were used to define sensitization, even when methodology was otherwise similar, or skin test and specific $\operatorname{IgE}$ results were combined. Only a study such as this, in which the same allergens and methodology were used in each centre, can overcome these problems.

The heterogeneity found in the estimates confirms that there is genuine variation between centres and countries, and that the lack of uniformity in reports from different studies was not an artefact of the reasons for noncomparability given above. In particular, heterogeneity explains why a large relation was found with Cladosporium sensitization in England [9], but no overall effect, although an explanation of why the heterogeneity occurs cannot be provided by these data alone. In Reykjavík, Iceland and Basle, Switzerland, with greater prevalence of sensitization to Cladosporium (table 2), there appeared to be no relation with BHR (fig. 2). There was no evidence, on plotting the results, for any relation between effect size and prevalence of sensitization, for Cladosporium, cat or timothy grass.

Sensitization as measured by specific IgE was used in preference to skin-prick tests because of difficulty in standardization of the latter [22], and because in the analysis of the English data alone the explained variation in BHR was not increased by inclusion of the additional allergens [9]. The fifth regional allergen tested for specific IgE was birch, Parietaria judaica or ragweed, according to individual country choice. In the analysis of the English data [9], sensitization to birch showed a negative relation with BHR, i.e. increased "slope" in sensitized subjects.

Some studies [6] have used a higher cut-off point for specific IgE for defining sensitization. The relations found here at the minimum detectable level after adjustment for degree of sensitization suggest that the minimum level should be used.

The conclusion from the English data that serum total $\mathrm{IgE}$ is not associated with BHR after adjusting for specific $\operatorname{IgE}$ can now be seen as a type II error. The consistent and highly significant relation shown in table 3 encompasses the nonsignificant estimate found previously [9]. SUNYER et al. [23] reported that asthma and asthma or BHR were associated with total IgE in the Spanish data after adjusting for specific IgE to five allergens. Total IgE was also found to be an independent determinant of BHR, after adjusting for specific IgE and skin-prick test-positivity, in the Italian data [7]. However, it cannot be ruled out that adjustment for further allergens would remove the relation of BHR to total IgE. Lack of power in individual studies may explain some nonsignificant results, but unless the effect size is reported it is not possible to distinguish between lack of power and genuine heterogeneity.

The results of the analysis of PD20 (not shown) were in accordance with those of "slope", but the analysis had less power, and could only be carried out by country, with some countries omitted in some analyses. "Slope" was developed for the ECRHS analyses [1, 15], and has been found here to be a powerful tool. Although use of a continuous outcome precludes estimation of attributable risk, as estimated in the Spanish data [4], the unimodal distribution of BHR [24, 25] militates against the use of any cut-off point. Percentage variation explained is the equivalent measure of population effect for a continuous outcome.

The results of the analysis of combinations of sensitization (table 5) served to show that the assumption of additivity underlying table 3 was reasonable, but as data for all centres could not be included in all of the comparisons, and degree of sensitization was not included, so the results in table 3 are more informative. Subjects sensitized to cat have, on average, a similar increase in BHR to those sensitized to house dust mite, but the prevalence of sensitization to cat is less than that to house dust mite (table 2). Although exposure at some point in life is a prerequisite for sensitization, there is limited information on the relation between prevalence of sensitization and prevalence of exposure. Table 6 shows that sensitization to house dust mite was associated with a greater population effect on BHR than sensitization to cat in more than half of the centres participating in the ECRHS.

The difference in the relation of BHR to any degree of sensitization to timothy grass, between those tested in the summer and winter months, was not statistically significant. This may have been due to lack of power to detect a difference. The "summer" estimate was more than twice the "winter" estimate and slightly greater than the increase in BHR associated with sensitization to cat or house dust mite.

Variation in bronchial hyperresponsiveness between centres and countries can to some extent be explained by variation in atopy, but the heterogeneity in the relations of bronchial hyperresponsiveness to individual allergens 
Table 6. - The explained total variation and change in variation in bronchial hyperresponsiveness, as measured by the European Community Respiratory Health Survey "slope", by specific immunoglobulin E (IgE) to four allergens

\begin{tabular}{|c|c|c|c|c|c|c|c|}
\hline \multirow{3}{*}{ Centre } & \multicolumn{2}{|c|}{ Total variation $\%$} & \multicolumn{5}{|c|}{ Change in variation explained $\%$} \\
\hline & \multirow{2}{*}{$\begin{array}{l}\text { No specific } \\
\text { IgE* }^{*}\end{array}$} & \multirow[t]{2}{*}{ All variables ${ }^{+}$} & \multicolumn{3}{|c|}{ No titre or sensitization } & \multirow{2}{*}{$\begin{array}{l}\text { No sensitization } \\
\text { to Cladosporium }\end{array}$} & \multirow{2}{*}{$\begin{array}{l}\text { Single variable } \\
\text { for atopy }\end{array}$} \\
\hline & & & HDM & Cat & Grass & & \\
\hline Reykjavík & 21.2 & 25.3 & -0.3 & -2.9 & -0.7 & 0.0 & -4.1 \\
\hline Bergen & 15.5 & 19.5 & -0.1 & -2.9 & -0.4 & -0.1 & -3.8 \\
\hline Gothenburg & 15.8 & 26.2 & -2.7 & -4.6 & -0.2 & -1.1 & -9.1 \\
\hline Umeå & 17.7 & 22.0 & -0.1 & -2.5 & -0.5 & -0.5 & 3.9 \\
\hline Uppsala & 19.2 & 24.2 & -0.5 & -2.2 & -1.8 & -0.1 & -3.5 \\
\hline Bergen op Zoom & 21.6 & 31.3 & -4.8 & 0.0 & -1.4 & -1.4 & -8.2 \\
\hline Geleen & 18.2 & 24.6 & -1.9 & -1.8 & -0.3 & 0.0 & -5.9 \\
\hline Groningen & 25.5 & 34.5 & -3.3 & -2.2 & -0.7 & -0.4 & -5.7 \\
\hline Antwerp & 11.4 & 19.1 & -0.9 & -1.7 & -1.5 & -0.3 & -5.6 \\
\hline South Antwerp & 15.9 & 22.5 & -0.7 & -2.7 & -3.5 & -0.2 & -5.5 \\
\hline Erfurt & 19.6 & 21.0 & -0.1 & -1.0 & 0.0 & 0.0 & -1.4 \\
\hline Hamburg & 24.4 & 27.1 & 0.0 & -2.4 & 0.0 & 0.0 & -2.2 \\
\hline Basle & 15.8 & 21.0 & -2.5 & -0.4 & -0.7 & 0.0 & -4.0 \\
\hline Bordeaux & 13.1 & 24.6 & -8.1 & -1.1 & -0.4 & 0.0 & -9.4 \\
\hline Grenoble & 22.1 & 25.2 & -0.2 & -0.2 & -0.8 & -0.3 & -2.4 \\
\hline Montpellier & 13.1 & 22.4 & -4.3 & -1.1 & -1.9 & -0.5 & -5.0 \\
\hline Paris & 15.3 & 25.0 & -3.7 & -3.7 & -0.4 & -0.2 & -4.3 \\
\hline Cambridge & 33.9 & 43.1 & -1.4 & -1.2 & -1.2 & -1.9 & -5.8 \\
\hline Ipswich & 30.4 & 43.1 & -4.2 & -0.8 & -2.1 & -2.5 & -10.0 \\
\hline Norwich & 23.5 & 30.0 & -2.7 & -0.3 & -0.8 & -0.3 & -2.7 \\
\hline Dublin & 21.2 & 32.6 & -8.0 & -1.0 & -2.4 & -0.7 & -10.4 \\
\hline Pavia & 17.8 & 23.8 & -0.4 & -1.8 & -2.2 & -0.2 & -5.1 \\
\hline Turin & 27.9 & 33.5 & -0.9 & -1.0 & -2.8 & -0.4 & -1.7 \\
\hline Verona & 24.6 & 31.1 & -2.4 & -0.5 & -3.2 & -0.5 & -4.7 \\
\hline Albacete & 25.0 & 31.2 & -2.5 & -1.1 & -3.2 & -0.3 & -4.7 \\
\hline Barcelona & 18.6 & 28.9 & -2.1 & -2.6 & -1.2 & -3.3 & -10.3 \\
\hline Galdakao & 19.9 & 25.0 & -4.2 & -0.3 & -0.8 & 0.0 & -4.0 \\
\hline Huelva & 22.4 & 34.2 & -3.8 & -2.0 & -5.2 & -0.1 & -5.5 \\
\hline Oviedo & 26.7 & 29.7 & -1.8 & -0.9 & -0.9 & -0.8 & -2.8 \\
\hline Christchurch & 22.1 & 28.8 & -2.2 & -0.7 & -1.1 & -1.3 & -5.1 \\
\hline Hawke's Bay & 27.9 & 38.8 & -4.7 & -0.1 & -4.1 & -0.2 & -10.1 \\
\hline Wellington & 22.4 & 30.8 & -5.6 & -0.8 & -0.5 & 0.0 & -6.5 \\
\hline Melbourne & 31.4 & 37.9 & -4.1 & -1.6 & -0.6 & -0.2 & -4.3 \\
\hline Portland & 14.5 & 18.7 & -1.0 & -0.7 & -1.9 & -0.7 & -2.3 \\
\hline
\end{tabular}

*: model included log total IgE adjusted for season of testing, baseline lung function, height, sex, age, smoking and age/sex and age/ smoking interactions; ${ }^{+}$: as first column plus titres of house dust mite (HDM), cat and timothy grass-specific IgE and sensitization to Cladosporium, HDM, cat and timothy grass. Locations of centres are shown in table 1.

means that quantifying the extent is not straightforward. When assessing the effects on bronchial responsiveness, atopy should not be defined as a positive result to any one of a panel of allergens, or degree by the number of positive results or the sum of skin-prick test weal diameters. First, the more allergens that are tested, the more likely an individual is to be reported atopic, although the evidence is that this effect is small beyond three or four common allergens. Secondly, the relation of bronchial responsiveness to sensitization is not positive for all allergens in all places. Thirdly, the size of relation varies beyond this, so the number of positive tests, or the sum of weal diameters, is a poor measure of degree of sensitization. This was shown directly by the reduction in variation in "slope" explained by atopy alone compared to the individual specific IgE variables. The relation of bronchial responsiveness to atopy should be reported as the mutually adjusted effects for individual allergens, and it is necessary to adjust in this way when investigating the relation of bronchial responsiveness to other potential risk factors.
List of principal participants. Co-ordinating Centre (London): $\mathrm{P}$. Burney, S. Chinn, C. Luczyrnska, D. Jarvis, E. Lai. Project Management Group: P. Burney (Project leader), S. Chinn, C. Luczyrnska, D. Jarvis, P. Vermeire (Antwerp), H. Kesteloot (Louvain), J. Bousquet (Montpellier), D. Nowak (Hamburg), ${ }^{\dagger}$ J. Prichard (Dublin), R. de Marco (Verona), B. Rijcken (Groningen), J.M. Anto (Barcelona), J. Alves (Porto), G. Boman (Uppsala), N. Nielsen (Copenhagen), P. Paoletti (Pisa). Participating Centres: W. Popp (Vienna, Austria); M. Abramson, J. Kutin (Melbourne, Australia); P. Vermeire, J. Weyln (South Antwerp, Antwerp, Belgium); J. Bousquet, J. Knani (Montpellier), F. Neukirch, R. Liard (Paris), I. Pin, C. Pison (Grenoble), A. Taytard (Bordeaux, France); H. Magnussen, D. Nowak (Hamburg), H-E. Wichmann, J. Heinrich (GSF Institute of Epidemiology, Erfurt, Germany); N. Papageorgiou, P. Avarlis, M. Gaga, C. Marossis (Athens, Greece); T. Gislason, D. Gislason (Reykjavk, Iceland); J. Prichard, S. Allwright, D. MacLeod (Dublin, Ireland); M. Bugiani, C. Bucca, C. Romano (Turin), R. de Marco Lo Cascio, C. Campello (Verona), A. Marinoni, I. Cerveri, L. Casali (Pavia, Italy); B. Rijcken, A. Kremer (Groningen, Bergen op Zoom, Geleen, the Netherlands); J. Crane, S. Lewis (Wellington, Christchurch, Hawke Bay, New Zealand); A. Gulsvik, E. Omenaas (Bergen, Norway); J.A. Marques, J. Alves (Porto, Portugal); J.M. Antó, J. Sunyer, F. Burgos, J. Castellsagué, J. Roca, J.B. Soriano, A. Tobás (Barcelona), N. Muniozguren, J. Ramos González, A. Capelastegui (Galdakao), J. Castillo, J. Rodriguez Portal (Seville), J. Martinez-Moratalla, E. Almar (Albacete), J. Maldonado Pérez, A. Pereira, J. Sánchez (Huelva), J. Quiros, I. Huerta, F. Pavo (Oviedo, Spain); G. 
Boman, C. Janson, E. Björnsson (Uppsala), L. Rosenhall, E. Norrman, B Lundbäck (Umea), N. Lindholm, P. Plaschke (Gothenburg, Sweden); U. Ackermann-Liebrich, N. Künzli, A. Perruchoud (Basle, Switzerland); M. Burr, J. Layzell (Caerphilly), R. Hall (Ipswich), B. Harrison (Norwich), J. Stark (Cambridge, UK); S. Buist, W. Vollmer, M. Osborne (Portland, OR, USA).

Financial support was provided by Allen and Hanbury's, Australia; Belgian Science Policy Office, National Fund for Scientific Research, Belgium; Ministère de la Santé, Glaxo France, Insitut Pneumologique d'Aquitaine, Contrat de Plan Etat-Région Languedoc-Rousillon, CNMATS, CNMRT (90MR/10, 91AF/6), Ministre delegué de la santé, RNSP, France; GSF and the Bundesminister für Forschung und Technologie, Bonn, Germany; The Greek Secretary General of Research and Technology, Fisons, Astra and Boehringer-Ingelheim, Greece; Bombay Hospital Trust, India; Ministero dell'Università e della Ricerea Scientifica e Tecnologica, CNR, Regione Veneto grant RSF No. 381/05.93, Italy; Asthma Foundation of New Zealand, Lotteries Grant Board, Health Research Council of New Zealand. Norwegian Research Council project No. 101422/310 New Zealand; Glaxo Farmaceutica, Sandoz, Portugal; Ministero Sanidad y Consumo FIS (grant Nos. 91/0016060/00E-05E and 93/0393) and grants from Hospital General de Albacete, Hospital General Juan Ramón Jiménenz, Consejeria de Sanidad Principado de Asturias, Spain; The Swedish Medical Research Council, the Swedish Heart Lung Foundation, the Swedish Association against Asthma and Allergy, Sweden; Swiss National Science Foundation grant 4026-28099; National Asthma Campaign, British Lung Foundation, Department of Health, South Thames Regional Health Authority, UK; United States Department of Health, Education and Welfare Public Health Service (grant No. 2 S07 RR05521-28).

Acknowledgements. The authors are grateful to ${ }^{\dagger} \mathrm{C}$. Baya and M. Hallen for their help during the study and to K. Vuylsteek and the members of the Comite d'Actions Concertées for their support. The co-ordination of this work was supported by the European Commission.

\section{References}

1. Chinn S, Burney P, Jarvis D, Luczynska C, on behalf of the European Community Respiratory Health Survey. Variation in bronchial responsiveness in the European Community Respiratory Health Survey (ECRHS). Eur Respir J 1997; 10: 2495-2501.

2. Burney PGJ, Britton JR, Chinn S, et al. Descriptive epidemiology of bronchial reactivity in an adult population: results from a community study. Thorax 1987; 42: $38-44$.

3. Trigg CJ, Bennett JB, Tooley M, Sibbald B, D'Souza MF, Davies RJ. A general practice based survey of bronchial hyperresponsiveness and its relation to symptoms, sex, age, atopy, and smoking. Thorax 1990; 45: 866-872.

4. Soriano JB, Tobias A, Kogevinas M, et al. and the Spanish group of the European Community Respiratory Health Survey. Atopy and nonspecific bronchial responsiveness: a population-based assessment. Am J Respir Crit Care Med 1996; 154: 1636-1640.

5. Boezen HM, Postma DS, Schouten JP, Kerstjens HAM, Rijcken B. PEF variability, bronchial responsiveness and their relation to allergy markers in a random population. Am J Respir Crit Care Med 1996; 154: 30-35.

6. Omenaas E, Bakke P, Eide GE, Elsayed S, Gulsvik A. Serum house dust mite antibodies: prediction of increased bronchial responsiveness in adults of a community. Eur Respir J 1996; 9: 919-925.

7. European Community Respiratory Health Survey (ECRHS) - Italy. Determinants of bronchial responsiveness in the European Community Respiratory Health Survey in Italy: evidence of an independent role of atopy, total ser- um IgE levels, and asthma symptoms. Allergy 1998; 53: 673-681.

8. European Community Respiratory Health Survey. The distribution of total and specific serum IgE in the European Community Respiratory Health Survey. J Allergy Clin Immunol 1997; 99: 314-322.

9. Chinn S, Jarvis D, Luczynska C, Burney P. Individual allergens as risk factors for bronchial responsiveness in young adults. Thorax 1998; 53: 662-667.

10. Peat JK, Tovey E, Gray EJ, Mellis CM, Woolcock AJ. Asthma severity and morbidity in a population sample of Sydney schoolchildren. Part II. Importance of house dust mite allergens. Aust NZ J Med 1994; 24: 270-276.

11. Sears MR, Herbison GP, Holdaway MD, Hewitt CJ, Flannery EM, Silva PA. The relative risks of sensitivity to grass pollen house dust mite and cat dander in the development of childhood asthma. Clin Exp Allergy 1989; 19: 419-424.

12. Burrows B, Sears MR, Flannery EM, Herbison GP, Holdaway MD. Relations of bronchial responsiveness to allergy skin test reactivity, lung function, respiratory symptoms, and diagnoses in thirteen-year-old New Zealand children. J Allergy Clin Immunol 1995; 95: 548-556.

13. Burney PGJ, Luczynska C, Chinn S, Jarvis D. The European Community Respiratory Health Survey. Eur Respir $J$ 1994; 7: 954-960.

14. United Medical and Dental Schools of Guy's and St. Thomas's Hospitals, Department of Public Health Medicine. Protocol for The European Community Respiratory Health Survey. ISBN 1869942019 London 1993.

15. Chinn S, Arossa WA, Jarvis DL, Luczynska CM, Burney PGJ. Variation in nebuliser aerosol output and weight output from the Mefar dosimeter: implications for multicentre studies. Eur Respir J 1997; 10: 452-456.

16. Chinn S. Choosing a transformation. Journal of Applied Statistics 1996; 23: 395-404.

17. Chinn S, Britton JR, Bumey PGJ, Tattersfield AE, Papacosta AO. Estimation and repeatability of the response to inhaled histamine in a community survey. Thorax 1987; 42: 45-52.

18. Quanjer PhH, Tammeling GJ, Cotes JE, Pedersen OF, Peslin R, Yernault J-C. Lung volumes and forced ventilatory flows. Eur Respir J 1993; 6: (Suppl. 16), 5-40.

19. Roca R, Burgos F, Sunyer J, et al. Reference values for forced spirometry. Eur Respir J 1998; 11: 1354-1362.

20. DerSimonian R, Laird N. Meta-analysis in clinical trials. Control Clin Trials 1986; 7: 177-188.

21. Spieksma FThM. Regional European Pollen Calendars. In: D'Amato G, Spieksma FThM, Bonini S, eds. Allergenic Pollen and Pollinosis in Europe. Oxford, Blackwell Scientific Publications, 1991.

22. Chinn S, Jarvis D, Luczynska CM, Lai E, Burney PGJ. Measuring atopy, in a multi-centre epidemiological study. Eur J Epidemiol 1996; 12: 155-162.

23. Sunyer J, Antó JM, Castellsagué J, Soriano JB, Roca J, and the Spanish group of the European Study of Asthma. Total serum IgE is associated with asthma independently of specific IgE levels. Eur Respir J 1996; 9: 1880-1884.

24. Cockcroft DW, Bersheid BA, Murdock KY. Unimodal distribution of bronchial responsiveness to inhaled histamine in a random human population. Chest 1983; 83: 751-754.

25. Rijcken B, Schouten JP, Weiss ST, Neinesz AF, de Vries $\mathrm{K}$, van der Lende $\mathrm{R}$. The distribution of bronchial responsiveness to histamine in symptomatic and asymptomatic subjects. Am Rev Respir Dis 1989; 140: 615-623. 